\title{
Is Innovation Destroying Jobs? Firm-Level Evidence from the EU
}

\author{
Mariacristina Piva ${ }^{1}$ and Marco Vivarelli ${ }^{2,3,4, *}$ \\ 1 Department of Economic Policy , Università Cattolica del Sacro Cuore, 29122 Piacenza, Italy; \\ mariacristina.piva@unicatt.it \\ 2 Department of Economic Policy, Università Cattolica del Sacro Cuore, 20123 Milano, Italy \\ 3 UNU-MERIT, 6211 Maastricht, The Netherlands \\ 4 IZA, 53113 Bonn, Germany \\ * Correspondence: marco.vivarelli@unicatt.it; Tel.: +39-02-7234-2921
}

Received: 28 February 2018; Accepted: 19 April 2018; Published: 21 April 2018

check for updates

\begin{abstract}
Using a unique firm-level database comprising the top European R\&D investors over the period 2002-2013 and running LSDVC estimates, this study finds a significant labor-friendly impact of R\&D expenditures. However, this positive employment effect appears limited in magnitude and entirely due to the medium- and high-tech sectors, while no effect can be detected in the low-tech industries. From a policy point of view, this outcome supports the EU2020 strategy but-taking into account that most European economies are specialized in low-tech activities-is also worrying in terms of future perspectives of the European labor market.
\end{abstract}

Keywords: R\&D; innovation; employment; firm-level analysis; EU

\section{Introduction}

The fear of mass technological unemployment is back.

In the 19th century, during the first industrial revolution, English manufacturing workers, under the charismatic lead of Ned Ludd, destroyed machineries, while their agricultural companions did the same with respect to the threshers under the command of Captain Swing [1,2]. New machineries and threshers determined new process innovations perceived as detrimental on employment.

Now, new products connected to ICT, such as robots, self-driving autonomous cars, and 3D printing machines, all of which are able to change production processes, have raised again the fear of imminent pervasive technological unemployment. Moreover, not only does manufacturing employment appear at risk, but jobs in services-including those requiring cognitive skills—are also no longer guaranteed (examples include IBM Watson Explorer displacing lawyers and doctors, and open online university courses-provided by top US universities—displacing university professors all over the world).

In this context, Brynjolfsson and McAfee [3,4] think that the origin of the present employment problem is a structural adjustment ("Great Restructuring") characterized by an exponential growth of ICT applications and computers' processing speed having an even larger impact on jobs, skills, and the whole economy. (In the US, Frey and Osborne [5] predict that almost half of the occupational categories are at risk of being automated. In Italy, for a recent assessment of the impact of ICT on the Italian economy, see Bonanno [6].). In addition, the slow recovery after the recent financial and economic crisis seems characterized by a worrisome jobless nature. Indeed, international organizations, such as European Commission, UNIDO, and OECD, are increasingly concerned with the issue of avoiding jobless growth [7-9]. 
Especially at the European level, the issue is relevant. Indeed, policy-makers need updated evidence on the relationship among innovation and employment in order to tailor policies that can support labor-friendly innovation. On this topic, there are already a number of studies; however, studies providing an overall picture of the European area are still scarce [10,11]. In addition, the industrial specialization may play a role suggesting a stronger or weaker relationship among innovation and employment within sectors. Therefore, this paper aims at providing additional light on potential different dynamics in more or less high-tech industries.

Under this scenario, the aim of this paper is twofold. On the one hand, the economic insights about the employment impact of technological change will be disentangled and previous empirical studies will be discussed (Section 2); on the other hand-using a unique dataset-a microeconometric empirical test will be provided, in order to shed some light on the recent evolution of the relationship between R\&D expenditures, considered the main intentional innovation input, and employment in Europe, both on aggregate and disentangling firms, according to their R\&D intensity (Sections 3 and 4).

\section{The Literature}

\subsection{Theory}

As stated in the OECD Oslo Manual [12] "Innovation is the implementation of a new or significantly improved product (good or service), or process, a new marketing method, or a new organizational method in business practices, workplace organization, or external relations." Indeed, especially product and process innovations (more in detail, "[a] product innovation is the introduction of a good or service that is new or significantly improved with respect to its characteristics or intended uses", and "[a] process innovation is the implementation of a new or significantly improved production or delivery method" [12]) are considered relevant, as they are able to significantly impact on production and employment.

The assessment of the impact of the multifaceted phenomenon of innovation on employment is a well-debated issue for theoretical economists. On the one hand, product innovations tend to have a labor-friendly nature. On the other hand, process innovations, frequently labor-saving, are considered responsible for technological unemployment, even if economic theory identifies the existence of indirect effects able to compensate for the reduction in employment associated with process innovation.

Product innovation, which is likely to be caused by R\&D investments, is the introduction of new products able to determine the emergence of new markets (see, for instance, the computer sector in the last decades of the 20th century). Such dynamics might cause a substantial job-creation effect $([13,14]$ vol. I). In the current debate, various researchers [15-20] agree that product innovations have a positive impact on employment since they open the way to the development of either new goods and/or markets. However, even the job-creating effect of product innovation may be more or less effective; in fact, the so-called "welfare effect" (the creation of new products and sectors) has to be compared with the "substitution effect", namely the displacement of mature products (for example, the MP3 music format is a product innovation currently displacing the compact disk, which, in turn, displaced vinyl records (dominant throughout the 20th century)) [11,21-23].

When turning to process innovation, the implementation of a new or significantly improved production method, its probable direct impact on employment is job destruction, as it is meant to produce the same amount of output using a lesser amount of production factors, in particular labor. However, the economic thought-since its very beginning-has shown the existence of economic forces that can compensate for the reduction in employment determined by technological progress. In the 19th century, classical economists designed a theory that Marx later called the "compensation theory" [14,24]. This theory is articulated in different market compensation mechanisms that can counterbalance the initial labor-saving impact of process innovation (for extensive surveys on the subject, see $[18,25,26]$ chap. 2, [27-30]). We now refer to the most relevant ones.

First of all, process innovation leads to a decrease in the unit costs of production, and, if market competitive forces are at work, this effect is translated into a decrease in prices. The decreasing prices 
stimulate a new demand for products and, in turn, additional production and employment ([31-33] chaps. 11, [11,12,34-36]). However, there are three drawbacks. Classical authors [37-39] have pointed out that the very first effect of a labor-saving technology is a decrease in the aggregate demand due to the cancellation of the demand coming from the dismissed workers. This shows that market clearing starts from a decreased demand that has to be more than counterbalanced. Moreover, the effectiveness of this mechanism depends on the hypothesis of perfect competition. If an oligopolistic regime is prevailing, the whole compensation is strongly weakened since cost savings are not necessarily translated into decreasing prices [40]. Finally, demand elasticity plays a crucial role in making this compensation mechanism more or less effective.

Nevertheless, in case the gap between costs and prices enlarges and the competitive convergence is not instantaneous, extra profits may accumulate by innovative entrepreneurs. According to the proponents of the compensation theory, these profits might be invested and, therefore, might generate new output and new jobs (see [41-43] and the more recent, [33]). This is the case of the compensation mechanism "via new investments." Indeed, it is clear that this mechanism relies on the unacceptable Say's law assumption that the accumulated profits (due to innovation) are immediately translated into additional investments. In contrast, pessimistic expectations ("animal spirits" in Keynesian thought) may imply the choice to delay investments even in the presence of cumulated profits obtained by innovation. A substantial delay in compensation may in turn generate structural technological unemployment.

To sum up, the economic theory available on the relationship between innovation and employment should be considered as a complex and multifaceted framework, where the labor-friendly nature of product innovation, the direct labor-saving impact of process innovation, and the compensation mechanisms and their drawbacks (which can weaken the effectiveness of such mechanisms) can combine in various ways, thus generating different and somehow unpredictable employment outcomes.

In fact, in different historical periods and different institutional and social contexts, the relative balance between the direct labor-saving effect of process innovation and the counterbalancing impacts of compensation forces and product innovation can considerably vary (for instance, the role of green innovation is now crucial, and in terms of likely employment impacts [44,45]) [15-17].

On the whole-though theoretical economists have developed articulate models about the employment impact of innovation-economic theory does not have a final clear-cut answer about the final employment effect of innovation, and attention should be turned to empirical analyses. (The empirical studies analyzing the link between technological change and employment have mainly focused on industrialized high-income countries, particularly OECD countries (basically because of better data availability); among the few recent articles dealing with DCs, see [46] for an application to the Turkish case, [47] for an analysis of the Indian case, and [48] for a study on the Ethiopian case.)

\subsection{Empirical Studies}

A number of empirical analyses have been proposed in recent decades. One of the main criteria to classify them is the level of investigation, whether macroeconomic, sectoral, or firm-based.

Country-level studies explore the direct effects and compensation mechanisms at work in the aggregate. While they are attractive from a theoretical point of view, on the minus side, the final employment national trends are co-determined by overwhelming institutional and macroeconomic determinants that are difficult to control for.

Sectoral-level works are able to capture the dominant relationship between innovation and employment having in the industry the unit of analysis. However, even in this case, the dynamics within each sector is ignored, and evidence might be the result of the aggregation in sectors.

Vice versa, microeconometric (firm-based) studies allow a direct firm-level mapping of innovation variables and can grasp the very nature of firms' innovative activities and their employment impact. However, two limitations are associated with this level of analysis. Firstly, the microeconomic approach 
cannot take fully into account the indirect compensation effects, which operate at sectoral and country levels. Secondly, even when the innovation is intrinsically labor-saving, microeconomic analyses generally show (see below) a positive link between technology and employment, since they do not take into account the effect on rivals crowded out by the innovative firms ("business stealing" effect).

Considering the macroeconometric studies, the oldest ones in this literature, Sinclair [49], putting forward a macro IS/LM scheme tested for US, concluded that a positive employment impact is assured if demand elasticity and the elasticity of factor substitution are sufficiently high. By the same token, Layard and Nickell [50] defined a demand for labor in a quasi-general equilibrium framework and stated that the crucial parameter is the elasticity of the demand for labor in response to a variation in the ratio between real wages and labor productivity. This elasticity should be high enough to fully compensate initial job losses as from the evidence they provided for the UK economy. In addition, Vivarelli [26] — running 3SLS regressions based on Italian and US data-found that the most effective compensation mechanism turned out to be connected to a decrease in prices connected to innovation in both countries. More recently, Feldmann [51]—using data on 21 industrial countries over the period 1985-2009-found that technological change significantly increases unemployment in the short term, with this impact fading away in the long run. In line with this approach, Matuzeviciute et al. [52], using panel data from 25 European countries for the period 2000-2012 and choosing alternative proxies for technological innovations (among others also R\&D was included), ran GMM-SYS estimates and found no significant relationship between technological innovations and unemployment. They also introduced time-lags as a robustness check.

On the whole, the (few) macroeconomic studies available reveal that technological progress does not seem to have a significant positive impact on unemployment. In addition, it can exhibit a labor-friendly nature when markets are characterized by competition and by a relatively high degree of substitutability between the production factors.

Switching to a more disaggregated level of analysis, the sectoral studies are particularly important in investigating the overall employment impact of innovation connected to the secular shift from manufacturing to services. Taking manufacturing and services jointly into account, Bogliacino and Pianta [20], considering industries in eight European countries in 1994-2004, found a positive employment impact of product innovation (which turned out particularly obvious in the high-tech manufacturing sectors). In addition, Bogliacino and Vivarelli [53], covering 25 manufacturing and service sectors for 15 European countries over the time-span 1996-2005, found that R\&D expenditures showed a job-creating effect, especially in high-tech industries. Interestingly enough, the labor-friendly nature of R\&D emerged in both their flow and the stock specifications. In addition, Piva and Vivarelli [54] updated (1998-2011) the previous analysis and provided evidence of a labor-friendly impact of R\&D expenditures. This positive employment effect appeared to be entirely due to mediumand high-tech sectors, while no effect was detected in low-tech industries. Moreover, capital formation was found to be negatively related to employment, suggesting the alleged labor-saving effect due to innovations embodied in physical capital. Cirillo et al. [55] investigated this issue over the last business cycles (2002-2007 and 2007-2011) in 36 manufacturing and service industries of five major European countries (Germany, France, Spain, Italy, and UK). In the upswing, product innovations turned out to positively affect the employment, especially the managerial category, while, in the downswing, product innovations lost their positive impact on jobs, and new processes drove restructuring and job destruction across all professional groups.

Summarizing the available sectoral evidence, a labor-saving tendency emerges in low- and medium-tech manufacturing, while a dominant labor-friendly impact has been detected in the high-tech manufacturing sectors and in the knowledge-intensive services, i.e., those sectors where product innovation is prevailing and demand is more dynamic.

Turning to microeconomic studies, which represent the main empirical reference for our empirical analysis, a flourishing literature can be considered. 
Van Reenen [56], in the case of UK, found evidence-using data from the SPRU innovation database covering the period 1976-1982-of a positive employment impact of innovation in manufacturing. This outcome turned out to be robust after controlling for fixed effects, dynamics, and endogeneity.

In the case of Italy, Piva and Vivarelli [57] found evidence in favor of a positive effect of gross innovative investment on employment, although particularly small in magnitude. Hall et al. [38] also found a positive employment impact of product innovation, but found no evidence of any employment displacement due to process innovation. Moreover, Barbieri et al. [58], using a panel data set covering 265 innovative firms over the period 1998-2010, showed a labor-friendly nature of R\&D entirely due to firms operating in high-tech industries and large companies, while no job creation due to technical change is detectable in traditional sectors or small and medium enterprises.

Turning our attention to the German case, Lachenmaier and Rottmann [59]—using a panel dataset of manufacturing firms over the period 1982-2002-found a significantly positive effect of different innovation measures on employment, but-partially in contrast with the theoretical expectations and previous empirical evidence- the authors found that process innovation had a higher positive impact than did product innovation.

Moving to Spain, Ciriaci et al. [60]—using matched waves of the annual Spanish Community Innovation Survey (CIS) - ran quantile regressions based on a comprehensive longitudinal sample of 3304 Spanish firms over the period 2002-2009. Their results provided evidence that innovative, smaller, and younger firms were more likely to show high and persistent employment growth episodes than non-innovative firms.

More interestingly, some recent studies are characterized by a multi-country approach. For instance, Bogliacino et al. [61] analyzed a longitudinal sample of European manufacturing and service firms over the period 1990-2008 and found a positive and significant employment effect of $R \& D$ expenditures in high-tech manufacturing and services but not in the more traditional (low- and medium-tech) manufacturing sectors.

Using CIS data from four European countries (France, Germany, Spain, and UK), Harrison et al. [11] showed that process innovation was responsible for employment displacement (although compensation mechanisms were at work), while product innovation was fundamentally labor-friendly.

Finally, Van Roy et al. [62] - using data on almost 20,000 European firms covering the period 2003-2012 - found that technological change (proxied by forward-citation weighted patents) was labor-friendly. However, this positive employment effect of innovation was found to be statistically significant only for firms in the high-tech manufacturing industries.

On the whole, previous firm-level studies provide regular evidence of a positive link between innovation and employment. However, this impact is particularly obvious when R\&D and/or product innovation are adopted as proxies of technological change and when high-tech sectors are considered (see Appendix A Table A1 for a synoptical view of the discussed studies).

\section{Data and Econometric Setting}

\subsection{The Data}

The original and unique dataset used in this study has been built on the basis of data provided by the Joint Research Center (JRC) of the European Commission, located in Sevilla (Spain). The starting point has been the JRC Scoreboard database comprising the top 1000 European (EU) R\&D investors-both in manufacturing and services-over the period 2002-2013 [63]. Therefore, we are necessarily focusing not just on innovative companies but on the innovative champions. (We are fully aware that there is a sort of sample bias due to impossibility to take into account non-innovative companies. However, our aim is to test the relationship between top innovators and employment at the European level.)

The JRC Scoreboard contains the following information: 
- company identification and sectoral classifications (both Industry Classification Benchmark (ICB) and NACE Rev.2 are available);

- basic economic data, including crucial information for this study, namely, net sales, capital formation, R\&D expenditures, and employment. However, with regard to the cost of labor-missing in the JRC Scoreboard - we had to use information (where available) downloaded from the Orbis database (Bureau Van Dijk; see below).

It is important to underline that the number of years available for each company depends on the company's history; more specifically, a firm enters the database when it first publishes a public financial statement and exits from it in case of bankruptcy, or because it exits from the relevant market or due to M\&A. Thus, the longitudinal database is unbalanced in nature.

Once we had acquired the rough original Scoreboard data, we proceeded to construct a consistent longitudinal database, adequate for running panel estimations intended to test the relationship between R\&D and employment. We adopted the following step-by-step procedure.

First Step: Data Extraction

We established the following criteria to guide the extraction of the data from the original Scoreboard files:

- We extracted information concerning net sales, capital formation, R\&D expenditures, and employment. (The R\&D expenditures parameter represents all costs related to the development of new products and services incurred during the year, being a genuine flow of current additional in-house $R \& D$ expenditures. Thus, our impact variable can be considered a better proxy of product than of process innovation; in fact, while we cannot exclude the fact that a portion of registered R\&D expenditures may be devoted to complementary process innovation, the adopted R\&D definition renders the expected correlation between such expenditures and product innovation much more straightforward.) Only firms with complete information were kept. At this stage, the sample was composed of 710 companies and 6170 observations.

- We expressed all value data in the current national currency. As all data within the Scoreboard are presented in euro (applying the last available exchange rate for non-euro countries), we transformed them back into nominal and national currency values.

Second Step: Deflation of Current Nominal Values

Nominal values were translated into constant price values through GDP deflators (source: http: //stats.oecd.org/) centered on the year 2010. For a tiny minority of firms reporting in currencies different from the national currency (i.e., 1 Belgian, 11 Dutch, 9 Irish, and 11 from Luxembourg reporting in US dollars), we opted to deflate the nominal values through the national GDP deflator as well.

Third Step: Values in PPP Dollars

Once we obtained constant 2010 price values, all figures were converted into US dollars using the PPP exchange rate in 2010 (source: http:/ /stats.oecd.org/). (This procedure is consistent with that suggested by the Frascati Manual [64] in order to adjust R\&D expenditures correctly for differences in price levels over time (i.e., intertemporal differences requiring deflation) and between countries (i.e., interspatial differences requiring a PPP equivalent). In particular “. . the Manual recommends the use of the implicit gross domestic product (GDP) deflator and GDP-PPP (purchasing power parity for GDP), which provide an approximate measure of the average real "opportunity cost" of carrying out the R\&D" (ibidem, p. 217). PPP dollars were chosen, since the US dollar is commonly considered the reference currency for global transactions, such as those carried out by the investigated firms, which are top world champions in terms of R\&D investment.) One company from Malta was excluded, due to the unavailability of PPP exchange rates from the OECD. The eight companies reporting figures in euro but 
located in non-euro countries (Denmark, Sweden, and UK) were excluded as well. The 58 European companies reporting in US dollars were, instead, kept as such.

Fourth Step: The Final Format of the Panel Data

The obtained unbalanced database comprises 701 companies, 2 codes (country and sector), and 4 variables (net sales, capital formation, $R \& D$ expenditures, and employment—cost of labor will be added as the very last step) over a period of 12 years (2002-2013).

Since we are interested in testing the labor impact of R\&D expenditures both in the aggregate and according to different technological levels, we endogenously ranked firms on the basis of their average (over the time-series available for each company) $R \& D$ intensity ( $\& D /$ net sales), defining firms as high-tech when their R\&D intensity is larger than $5 \%$, medium-tech if $R \& D$ intensity is between $1 \%$ and $5 \%$, and low-tech if the R\&D intensity is less than $1 \%$. (Moreover, a tout-court sectoral splitting may be highly biased when, for instance, a low-tech sector might be entirely represented by few R\&D global leaders. Therefore, this approach allows one to classify companies within the sample, including the top R\&D performers. Nevertheless, in comparative terms, our endogenous classification is sufficiently consistent with the sectoral Eurostat classification, since the resulting HT firms are especially concentrated in Electronic \& Electrical Equipment, Health Care Equipment \& Services, Pharmaceuticals \& Biotechnology, Software \& Computer Services, and Technology Hardware \& Equipment. Firms codified as MT are mainly present in Automobiles \& Parts, Chemicals, Construction \& Materials, Electronic \& Electrical Equipment, and Industrial Engineering. In the case of LT firms, the most represented industries are Construction \& Material, Food Producers, Forestry \& Paper, and Oil \& Gas Producers.) This classification is fully consistent with the JRC-IPTS Scoreboard report (see [54], which uses the same approach) and allows one to properly rank companies belonging to service sectors that turn out to be very heterogeneous in their R\&D intensity. Indeed, the Scoreboard dataset is not representative from a sectoral point of view, since it only comprises top world champions in terms of R\&D investment, irrespective of their industrial code. In this context, a "traditional" sectoral classification turns out to be not fully adequate to test the possible different job-creation impact of different levels of R\&D investment.

Since the following econometric exercise is based on a standard dynamic specification of the demand for labor, and given the unbalanced nature of our longitudinal database, the inclusion of the lagged dependent variable in the estimated specification involved both a reduction in the number of firms (retaining only those firms with at least two consecutive employment data) and a further decrease in the number of observations (we lost 27 companies in this step).

Therefore, we ended up with 674 companies for a total of 5222 observations. Since the consideration of the labor-cost variable would have implied a dramatic decrease in terms of the amount of information (see below), we have opted to firstly run our regressions without the wage control and then to include the additional variable and test again the extended specification.

Table 1 reports the distribution of the retained firms across the different European countries (bearing in mind that all included firms are quoted, some countries (such as the UK), where stock exchange quotation is more common, turn out to be over-represented).

As mentioned above, we tried to go beyond the Scoreboard data limitations (in order to properly test Equation (1) below), implementing a proxy for the cost of labor.

In particular, we have proceeded to match the Scoreboard dataset with the Orbis database (Bureau van Dijk), in order to get the cost of labor as reported in the balance sheets of the available companies.

Unfortunately, this merging has implied an important loss in terms of number of firms and information: Orbis information was accessible for only 360 Scoreboard companies, for a total of 2708 observations, over the shrunken period 2006-2013. The methodological steps discussed in details above were applied to the wage variable, as well. 
Table 1. Sample composition.

\begin{tabular}{ccc}
\hline Country & Firms & Obs. \\
\hline AUT & 25 & 189 \\
BEL & 23 & 197 \\
CZE & 1 & 6 \\
DEU & 142 & 1,016 \\
DNK & 20 & 174 \\
ESP & 18 & 147 \\
FIN & 40 & 379 \\
FRA & 101 & 855 \\
HUN & 1 & 8 \\
IRL & 17 & 132 \\
ITA & 37 & 239 \\
LUX & 11 & 37 \\
NLD & 37 & 261 \\
POL & 2 & 5 \\
POR & 4 & 25 \\
SVN & 2 & 12 \\
SWE & 58 & 454 \\
UK & 135 & 1,086 \\
EU & $\mathbf{6 7 4}$ & $\mathbf{5 2 2 2}$ \\
\hline
\end{tabular}

Table 2 reports the descriptive statistics.

Table 2. Descriptive statistics.

\begin{tabular}{lcccc}
\hline \multicolumn{1}{c}{ Variable } & Mean [Sd. Dev.] & HT & MT & LT \\
\hline \multirow{2}{*}{ Employment (E) } & $26,806.41$ & $13,051.41$ & $24,573.43$ & $51,551.35$ \\
& {$[58,222.51]$} & {$[37,927.61]$} & {$[48,382.33]$} & {$[85,413.83]$} \\
\hline \multirow{2}{*}{ Net Sales (Y) } & $15,706.89$ & 6250.47 & $10,916.63$ & $37,290.42$ \\
& {$[48,695.94]$} & {$[25,523.73]$} & {$[27,117.59]$} & {$[82,183.41]$} \\
\hline \multirow{2}{*}{ Capital Formation (I) } & 1096.95 & 333.65 & 654.96 & 2987.39 \\
& {$[4094.32]$} & {$[1844.97]$} & {$[2357.12]$} & {$[7105.21]$} \\
\hline \multirow{2}{*}{ Research \& Development expenditures (R\&D) } & 404.85 & 636.07 & 294.33 & 134.43 \\
& {$[2002.14]$} & {$[2988.22]$} & {$[896,70]$} & {$[343.06]$} \\
\multirow{2}{*}{ Cost of labor per employee (W) } & 112.92 & 124.92 & 120.11 & 80.91 \\
& {$[341.99]$} & {$[210.40]$} & {$[488.29]$} & {$[122.71]$} \\
\hline Obs. & {$[$ Obs. 2708] } & {$[$ Obs. 978] } & {$[$ Obs. 1037] } & {$[$ Obs. 693] } \\
\hline
\end{tabular}

\subsection{Econometric Strategy}

Since our dependent variable (employment) is highly persistent, as common in the literature using longitudinal data (since [56] onward, see Section 2), we adopt a dynamic employment equation, where employment is autoregressive and depends on the cost of labor, output, investment, and RED expenditures, which is our direct measure for innovation. Therefore, the estimated equation is a dynamic labor demand, augmented with technology:

$$
\begin{gathered}
\ln \left(E_{i j t}\right)=\rho \ln \left(E_{i j t-1}\right)+\alpha_{0}+\alpha_{1} \ln \left(W_{i j t}\right)+\alpha_{2} \ln \left(Y_{i j t}\right)+\alpha_{3} \ln \left(I_{i j t}\right)+ \\
\alpha_{4} \ln \left(R \& D_{i j t}\right)+\beta \prime C+\gamma^{\prime T}+\varepsilon_{i j}+u_{i j t}
\end{gathered}
$$

where $i, j$, and $t$ indicate, respectively, firm, country, and year; $E$ is employment, $W$ is the cost of labor per employee, $Y$ is net sales, $I$ is capital formation, $R E D$ is straightforward, $C$ is a set of country dummies, $T$ is a set of time dummies, and the last two terms $(\varepsilon$ and $u$ ) are the components of the error term (the set of country dummies control for the possible impact of different national macroeconomic 
climates, and specific economic policies, while the set of time dummies capture both the economic business cycle and possible supply side effects in the European labor market).

We expect a positive and high coefficient for the lagged term, a negative $\alpha_{1}$ capturing the standard labor demand inverse relationship between wages and employment, and a positive $\alpha_{2}$ capturing the role of final demand. A priori, $\alpha_{3}$ has no obvious sign, since capital formation is labor-expanding through its expansionary effect and labor-saving through process innovation embodied in the new machineries (see Section 2.1). Finally, our main interest is in $\alpha_{4}$, linking R\&D with employment: consistently with the previous literature and taking into account that $R \& D$ is more related with product rather than process innovation, we expect a positive sign for $\alpha_{4}$ (see Section 2).

As is well known, the dynamic specification (1) cannot be properly estimated either by Pooled Ordinary Least Squares (POLS) or by the Within Group (fixed effects, WG) estimator. Indeed, a common problem with this kind of dynamic specification concerns the endogeneity of the lagged dependent variable, leading to its overestimation in the POLS case and underestimation in the WG case. To control for this problem and to obtain consistent estimates, it is necessary to rely on instrumental variable (IV) techniques. In particular, Arellano and Bond [64] introduced the GMM-DIF estimator as a suitable methodology for dealing with the endogeneity of the lagged dependent variable (indeed, the demand for labor-which is the baseline for our specification (1) — was put forward by Arellano and Bond [64] as the key example of a dynamic specification, where the GMM-DIF methodology is necessary), while Blundell and Bond [65] improved the DIF-estimator, developing the GMM-SYS estimator, more appropriate in the case of high persistency of the dependent variable and when the cross-section dispersion of the data is overwhelming their time-series variability.

However, the recent econometric literature has come to the conclusion that both the GMM-DIF and the GMM-SYS estimators perform poorly when the longitudinal dataset in use is characterized by a low number of individuals. This is indeed our case, since we start from a relatively small number of firms (674), dropping to a very small sample size when dealing with companies split by R\&D intensity (see Table 4) and even less when we implement data on the cost of labor (see Table 5).

Therefore, we have used the Least Squares Dummy Variable Corrected (LSDVC) estimator, proposed by Kiviet [66], Judson and Owen [67], and Bun and Kiviet [68] as a suitable methodology in the case of panels characterized by a low number of individuals, where GMM cannot be used efficiently. The procedure is initialized by a standard panel estimate (in our case, the GMM-SYS one, given the high persistency of our dependent variable) and then relies on a recursive correction of the bias of the baseline fixed effects (FE) estimator.

An important methodological extension, allowing the LSDVC methodology to be applied to unbalanced panels, such as the one used in this study, has been provided by Bruno [69,70]. The author tested the behavior of unbalanced small samples through Monte Carlo experiments and highlighted the fact that the LSDVC estimator is preferred to both the LSDV estimator and the GMM estimators when the number of individuals is small and the degree of unbalancing is severe [69], two conditions which are verified in our database.

Finally, consistently with Bun and Kiviet [66] who have shown that estimated asymptotic standard errors may prove to be poor approximations in small samples, the statistical significance of our LSDVC coefficients has been tested using bootstrapped standard errors (running 50 iterations; see also Reference [69]).

\section{Results}

The dynamic specification (1) has been initially estimated dropping the variable concerning the cost of labor, since it is missing in the original Scoreboard dataset.

Table 3 reports the econometric results from POLS, FE, and LSDVC regressions, run on the whole sample. As discussed in the previous section, our attention will focus on the most reliable LSDVC estimates; POLS and FE estimates are reported for completeness. (Moreover, we can test whether the LSDVC coefficient of the lagged dependent variable correctly lies between the FE coefficient (characterized 
by a downward bias) and the POLS coefficient (characterized by an upward bias). As can be seen in Table 3, this is the case; this outcome is reassuring about the adopted econometric methodology.)

Table 3. Dependent variable: the number of employees in log scale.

\begin{tabular}{cccc}
\hline & $\mathbf{( 1 )}$ & $\mathbf{( 2 )}$ & $\mathbf{( 3 )}$ \\
& POLS & FE & LSDVC \\
\hline \multirow{2}{*}{$\log \left(E_{i j t-1}\right)$} & $0.909^{* * *}$ & $0.547^{* * *}$ & $0.604^{* * *}$ \\
& {$[0.006]$} & {$[0.108]$} & {$[0.016]$} \\
\hline \multirow{2}{*}{$\log \left(Y_{i j t}\right)$} & $0.058^{* * *}$ & $0.319^{* * *}$ & $0.307^{* * *}$ \\
& {$[0.007]$} & {$[0.069]$} & {$[0.014]$} \\
\hline \multirow{2}{*}{$\log \left(I_{i j t}\right)$} & 0.005 & $0.043^{* * *}$ & $0.045^{* * *}$ \\
& {$[0.004]$} & {$[0.008]$} & {$[0.009]$} \\
\hline \multirow{2}{*}{$\log \left(R \& D_{i j t}\right)$} & $0.010^{* * *}$ & $0.034^{* * *}$ & $0.029^{* * *}$ \\
& {$[0.003]$} & {$[0.012]$} & {$[0.008]$} \\
\hline $\mathrm{T}$ & Yes & Yes & Yes \\
\hline $\mathrm{C}$ & Yes & 5222 & 4793 \\
\hline Initial estimator & 5222 & & GMM-SYS
\end{tabular}

Notes: E stands for number of employees, Y for Net Sales I for capital formation, and R\&D for Research and Development expenditures. Robust standard errors in brackets. ${ }^{*}, * *$, and ${ }^{* * *}$ indicate significance respectively at $10 \%, 5 \%$ and $1 \%$. In the LSDVC estimate, bootstrapped standard errors are reported in brackets (50 iterations). Due to the instrumentation procedure and the unbalanced nature of the sample, there is a reduction in observations in the LSDVC estimate.

As can be seen, the results are in line with the theoretical expectations and with most previous econometric outcomes discussed in Section 2.2: the demand for labor appears to be auto-regressive and positively and significantly affected by both output and investment. Therefore, at least in the empirical context of this study, the labor-expanding expansionary effect seems to dominate a possible labor-saving impact due to the implementation of process innovation embodied in capital formation.

Turning our attention to the key regressor, R\&D expenditures positively and significantly (99\%) affect employment levels, with an elasticity equal to $2.9 \%$. Interestingly enough, these results are very much in line with previous literature, even in terms of the magnitude of the R\&D coefficient (see Reference [10], p. 58, Table 1, first column).

Using the R\&D intensity grouping criterion discussed in Section 3.1, we were then able to run our estimates for high-, medium- and low-tech firms, separately. Results are presented in Table 4.

Interestingly enough, while the other three coefficients do not exhibit substantial differences across firms of different technological intensity, the key employment/R\&D elasticity turns out to be highly significant $(99 \%)$ and larger in magnitude $(8.9 \%)$ in the HT firms, smaller $(6.6 \%)$ and less significant (95\%) in the MT companies, and not significant at all in the low-tech firms. This means that the overall labor-friendly nature of R\&D expenditures shown in Table 3 is entirely due to the high- and medium-tech firms, while no significant employment impact is detectable in the low-tech companies. This outcome is consistent with that obtained by some recent studies [53,61,71]. 
Table 4. Dependent variable: the number of employees in log scale.

\begin{tabular}{cccc}
\hline & $\mathbf{( 1 )}$ & $\mathbf{( 2 )}$ & $\mathbf{( 3 )}$ \\
& LSDVC & LSDVC & LSDVC \\
& $\mathbf{H T}$ & $\mathbf{M T}$ & $\mathbf{L T}$ \\
\hline $\log \left(E_{i j t-1}\right)$ & $0.608^{* * *}$ & $0.351^{* * *}$ & $0.914^{* * *}$ \\
& {$[0.023]$} & {$[0.028]$} & {$[0.025]$} \\
\hline $\mathrm{c} \log \left(Y_{i j t}\right)$ & $0.254^{* * *}$ & $0.516^{* * *}$ & 0.050 \\
& {$[0.026]$} & {$[0.044]$} & {$[0.054]$} \\
\hline $\log \left(I_{i j t}\right)$ & $0.047^{* * *}$ & $0.038^{* *}$ & $0.059 * * *$ \\
& {$[0.008]$} & {$[0.019]$} & {$[0.032]$} \\
\hline $\log \left(R \& D_{i j t}\right)$ & $0.089^{* * *}$ & $0.066^{* *}$ & 0.010 \\
& {$[0.025]$} & {$[0.032]$} & {$[0.022]$} \\
\hline $\mathrm{T}$ & Yes & Yes & Yes \\
$\mathrm{N}$ Obs & 1867 & 1851 & 1075 \\
Initial estimator & GMM-SYS & GMM-SYS & GMM-SYS \\
\hline
\end{tabular}

Notes: E stands for number of employees, Y for Net Sales, I for gross fixed capital formation, and R\&D for Research and Development expenditures. Bootstrapped standard errors in brackets (50 iterations). ${ }^{*}, * *$, and ${ }^{* *}$ stand for statistical significance respectively at $10 \%, 5 \%$ and $1 \%$.

Table 5 reports the results using the shrunken dataset obtained by the merging of the Scoreboard database with the Orbis one (see Section 3.1). As can be seen, the estimates about the controls are confirmed, while the additional wage term turns out to be negative and highly significant, as expected. Interestingly enough, notwithstanding the important decrease in terms of number of observations, R\&D expenditures continue to impact job creation (elasticity equals $3.4 \%$ at a $99 \%$ level of significance for the whole sample). However, this labor-friendly effect is limited to high-tech companies, where the relevant elasticity keeps its $99 \%$ level of confidence and rises to a magnitude equal to almost $17 \%$; in contrast, R\&D expenditures do not significantly affect employment levels either in the medium- or in the low-tech firms.

Table 5. Dependent variable: the number of employees in log scale.

\begin{tabular}{ccccc}
\hline & $\mathbf{( 1 )}$ & $\mathbf{( 2 )}$ & $\mathbf{( 3 )}$ & $\mathbf{( 4 )}$ \\
& LSDVC & LSDVC & LSDVC & LSDVC \\
& WHOLE SAMPLE & HT & MT & LT \\
\hline \multirow{2}{*}{$\log \left(E_{i j t-1}\right)$} & $0.588^{* * *}$ & $0.518^{* * *}$ & $0.765^{* * *}$ & $0.623^{* * *}$ \\
& {$[0.026]$} & {$[0.033]$} & {$[0.039]$} & {$[0.046]$} \\
\hline \multirow{2}{*}{$\log \left(W_{i j t}\right)$} & $-0.177^{* * *}$ & $-0.178^{* * *}$ & $-0.109^{* * *}$ & $-0.393^{* * *}$ \\
& {$[0.010]$} & {$[0.019]$} & {$[0.021]$} & {$[0.043]$} \\
\hline \multirow{2}{*}{$\log \left(Y_{i j t}\right)$} & $0.299^{* * * *}$ & $0.225^{* * *}$ & $0.313^{* * *}$ & $0.357^{* * *}$ \\
$\log \left(I_{i j t}\right)$ & {$[0.018]$} & {$[0.038]$} & {$[0.040]$} & {$[0.045]$} \\
\hline \multirow{2}{*}{$\log \left(R \& D_{i j t}\right)$} & $0.033^{* * *}$ & $0.026^{* * *}$ & 0.016 & $0.045^{* * *}$ \\
\hline T & {$[0.008]$} & {$[0.010]$} & {$[0.015]$} & {$[0.015]$} \\
\hline $\mathrm{N}$ Obs & $0.034^{* * *}$ & $0.168^{* * *}$ & 0.034 & 0.005 \\
Initial estimator & {$[0.009]$} & {$[0.037]$} & {$[0.025]$} & {$[0.012]$} \\
\hline Yes & GMM-SYS & GMM-SYS & GMM-SYS & GMM-SYS \\
\hline
\end{tabular}

Notes: E stands for number of employees, $\mathrm{W}$ for cost of labor per employee, $\mathrm{Y}$ for Net Sales, I for gross fixed capital formation, and R\&D for Research and Development expenditures. Bootstrapped standard errors in brackets (50 iterations). - ***, and ${ }^{* * *}$ stars stand for statistical significance respectively at $10 \%, 5 \%$ and $1 \%$. 


\section{Conclusions, Policy Implications, and Caveat}

The economic theory about the relationship between technological change and employment reveals that process innovation should imply a labor-saving effect, while product innovation should foster job creation; however, together with their labor-saving impact, process innovations involve decreasing prices and increasing investments and these in turn boost an increase in demand and production that can compensate initial job losses.

On the other hand, these compensation mechanisms can be hindered by the existence of severe drawbacks (such as imperfect competition or negative expectations), and their efficacy depends on crucial parameters (such as demand elasticity and the degree of substitutability between the production factors) and on the different institutional and socio-economic contexts.

Therefore, in different historical periods and institutional frameworks, the balance between the direct labor-saving effect of process innovation, the counterbalancing impacts of compensation forces and the job-creation impact of product innovation can be substantially different; therefore, the actual employment outcome of technological change becomes a relevant matter for empirical studies.

As far as previous microeconometric studies are concerned (see Section 2.2), the extant literature provides consistent evidence of a positive link between innovation and employment, which is more significant when R\&D and/or product innovation are adopted as proxies of technological change and when high-tech sectors are singled out.

Consistently with previous literature, this study also finds a significant labor-friendly impact of $R \& D$ expenditures; however, this positive employment effect appears limited in magnitude and entirely due to the medium- and high-tech firms, while no effect could be detected in the low-tech companies.

From a policy point of view, this outcome proves that the aim of the EU2020 strategy [65]-that is to develop an European economy based on R\&D, knowledge, and innovation-points in the right direction also in terms of job creation. Indeed, the evidence provided in this study supports the view that R\&D expenditures are beneficial not only to European productivity and competitiveness, but also to European job creation capacity, at least at the firm-level.

However, this policy implication should be qualified at least in three important respects. Firstly, this study is conducted at the firm level, so results cannot be easily extended at the macroeconomic/aggregate level, also taking into account the data limitations in terms of country coverage and the representativeness of our sample, which is unbalanced in favor of the top European R\&D performers.

Secondly, in this study, we use only one (although relevant) indicator to proxy innovation, namely $R \& D$ expenditures. Since this proxy is mostly related to labor-friendly product innovation, this study underscores the alternative mode of technological change that is labor-saving process innovation (see Section 2.1).

Thirdly, what emerges clearly from the empirical analysis is that the job-creation impact of R\&D expenditures is not equally detectable across different companies. More specifically, it is obvious for high- and (to a lesser extent) medium-tech firms, but absent in the low-tech ones. Taking into account that most EU economies are specialized in traditional activities, this is somehow worrying in terms of the future perspectives of European employment.

Acknowledgments: The Joint Research Center (JRC) of the European Commission (Sevilla, Spain) is gratefully acknowledged for providing us with the original Scoreboard dataset, within the JRC-IPTS research project: "A reappraisal of the impact of Corporate R\&D and Innovation on Employment." Moreover, the authors would like to thank the four anonymous referees for their very useful suggestions.

Author Contributions: Marco Vivarelli conceived and designed the empirical analysis; Mariacristina Piva analyzed the data and performed the econometric analysis. Both authors reviewed and edited the manuscript, and read and approved the final manuscript.

Conflicts of Interest: The authors declare no conflict of interest. 


\section{Appendix}

Table A1. Synoptical analysis of previous studies.

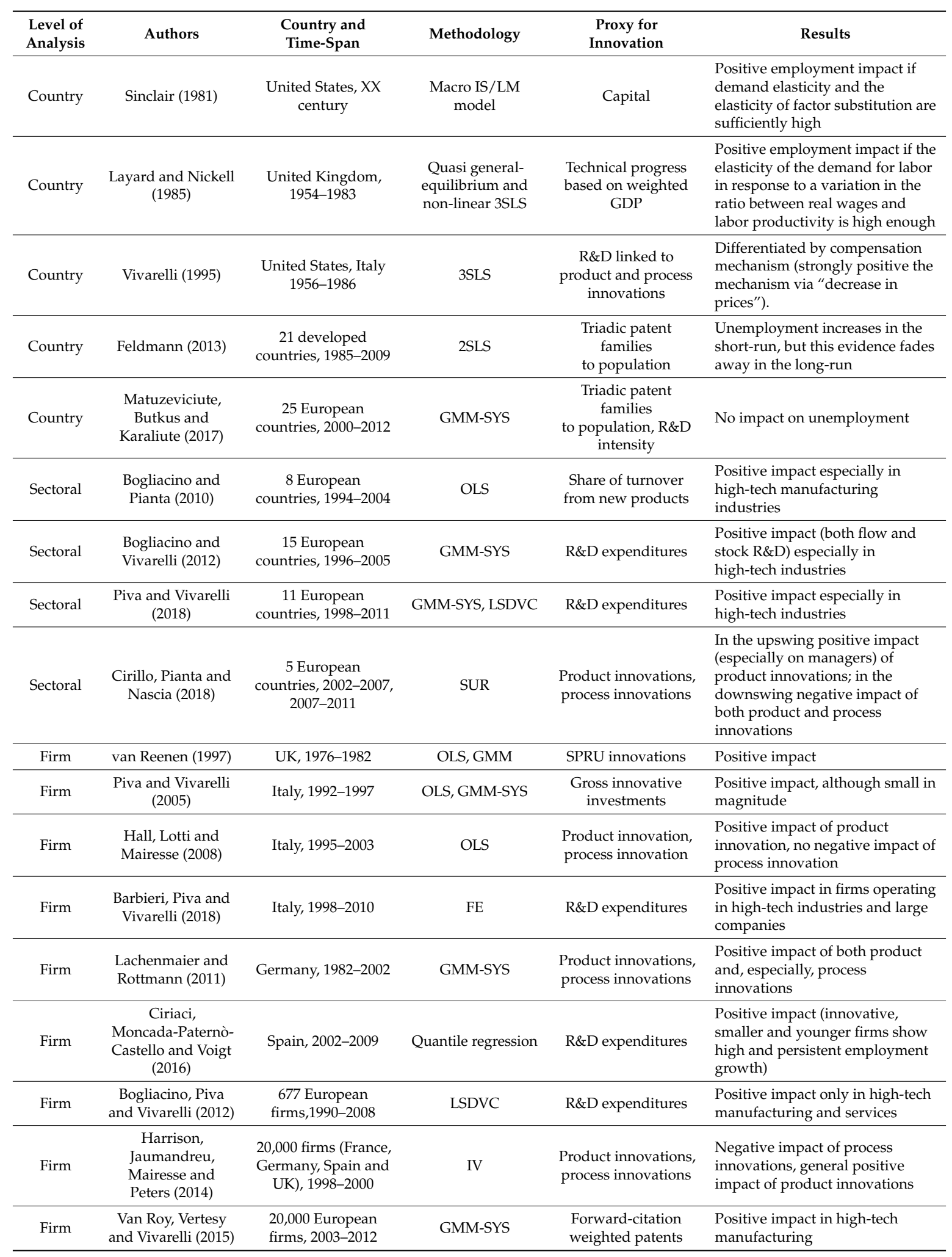




\section{References}

1. Hobsbawm, E.J. Industry and Empire: An Economic History of Britain since 1750; Penguin Books: London, $\mathrm{UK}, 1968$.

2. Hobsbawm, E.J.; Rudé, G. Captain Swing; London Reader's Union: London, UK, 1969.

3. Brynjolfsson, E.; McAfee, A. Race against the Machine: How the Digital Revolution is Accelerating Innovation, Driving Productivity, and Irreversibly Transforming Employment and the Economy; Digital Frontier Press: Lexington, MA, USA, 2011.

4. Brynjolfsson, E.; McAfee, A. The Second Machine Age: Work, Progress, and Prosperity in a Time of Brilliant Technologies; W.W. Norton: New York, NY, USA, 2014.

5. Frey, C.B.; Osborne, M.A. The future of employment: How susceptible are jobs to computerisation? Technol. Forecast. Soc. Chang. 2017, 114, 254-280. [CrossRef]

6. Bonanno, G. ICT and R\&D as Inputs or Efficiency Determinants? Analysing Italian Manufacturing Firms (2007-2009). Eurasian Bus. Rev. 2016, 6, 383-404. [CrossRef]

7. European Commission. Communication from the Commission to the European Parliament, the Council, the European Economic and Social Committee and the Committee of the Regions. In Europe 2020 Flagship Initiative Innovation Union; COM(2010) 546 Final; European Commission: Brussels, Belgium, 2010.

8. United Nations Industrial Development Organization. Industrial Development Report 2013. Sustaining Employment Growth: The Role of Manufacturing and Structural Change; UNIDO: Vienna, Austria, 2013.

9. Organisation for Economic Cooperation and Development. ICT and Jobs: Complements or Substitutes? The Effects of ICT Investment on Labour Market Demand by Skills and by Industry in Selected OECD Countries; 2016 Ministerial Meeting on the Digital Economy Technical Report; OECD: Paris, France, 2016.

10. Bogliacino, F.; Piva, M.; Vivarelli, M. R\&D and employment: An application of the LSDVC estimator using European data. Econ. Lett. 2012, 116, 56-59. [CrossRef]

11. Harrison, R.; Jaumandreu, J.; Mairesse, J.; Peters, B. Does innovation stimulate employment? A firm-level analysis using comparable micro-data from four European countries. Int. J. Ind. Org. 2014, 35, $29-43$. [CrossRef]

12. Organisation for Economic Cooperation and Development. The Measurement of Scientific and Technological Activities: Guidelines for Collecting and Interpreting Innovation Data: Oslo Manual, 3rd ed.; OECD: Paris, France, 2005.

13. Say, J.B. A Treatise on Political Economy or the Production, Distribution and Consumption of Wealth; First Edition 1803; M. Kelley: New York, NY, USA, 1964.

14. Marx, K. Capital; First Edition 1867; Foreign Languages Publishing House: Pyongyang, Korea, 1961.

15. Freeman, C.; Clark, J.; Soete, L. Unemployment and Technical Innovation; Pinter Publishers: London, UK, 1982.

16. Freeman, C.; Soete, L. (Eds.) Technical Change and Full Employment; Basil Blackwell: Oxford, UK, 1987.

17. Freeman, C.; Soete, L. Work for All or Mass Unemployment? Computerised Technical Change into the Twenty-First Century; Pinter Publishers: London, UK, 1994.

18. Vivarelli, M.; Pianta, M. (Eds.) The Employment Impact of Innovation: Evidence and Policy; Routledge: Abingdon-on-Thames, UK, 2000.

19. Edquist, C.; Hommen, L.; McKelvey, M. Innovation and Employment: Product Versus Process Innovation; Edward Elgar Publishing: Cheltenham, UK, 2001.

20. Bogliacino, F.; Pianta, M. Innovation and employment. A reinvestigation using revised Pavitt classes. Res. Policy 2010, 39, 799-809. [CrossRef]

21. Katsoulacos, Y.S. Product innovation and employment. Eur. Econ. Rev. 1984, 26, 83-108. [CrossRef]

22. Katsoulacos, Y.S. The Employment Effect of Technical Change; Wheatsheaf: Borough, London, 1986.

23. Hall, B.H.; Lotti, F.; Mairesse, J. Employment, innovation, and productivity: Evidence from Italian microdata. Ind. Corp. Chang. 2008, 17, 813-839. [CrossRef]

24. Marx, K. Theories of Surplus Value; First Edition 1905-1910; Lawrence \& Wishart: London, UK, 1969.

25. Petit, P. Employment and Technological Change. In Handbook of the Economics of Innovation and Technological Change; Stoneman, P., Ed.; Wiley-Blackwell: North Holland, The Netherlands, 1995; pp. 366-408.

26. Vivarelli, M. The Economics of Technology and Employment: Theory and Empirical Evidence; Edward Elgar Publishing: Cheltenham, UK, 1995. 
27. Pianta, M. Innovation and Employment. In Handbook of Innovation; Fagerberg, J., Mowery, D., Nelson, R.R., Eds.; Oxford University Press: Oxford, UK, 2005; pp. 568-598.

28. Coad, A.; Rao, R. The firm-level employment effects of innovations in high-tech US manufacturing industries. J. Evol. Econ. 2011, 21, 255-283. [CrossRef]

29. Vivarelli, M. Technology, employment and skills: An interpretative framework. Eurasian Bus. Rev. 2013, 3, 66-89. [CrossRef]

30. Vivarelli, M. Innovation, employment and skills in advanced and developing countries: A survey of economic literature. J. Econ. Issues 2014, 48, 123-154. [CrossRef]

31. Pigou, A. The Economics of Welfare; First Edition 1920; Macmillan: London, UK, 1962.

32. Neary, J.P. On the short-run effects of technological progress. Oxf. Econ. Pap. 1981, 33, 224-233. [CrossRef]

33. Stoneman, P. The Economic Analysis of Technological Change; Oxford University Press: Oxford, UK, 1983.

34. Hall, P.H.; Heffernan, S.A. More on the employment effects of innovation. J. Dev. Econ. 1985, 17, 151-162. [CrossRef]

35. Dobbs, I.M.; Hill, M.B.; Waterson, M. Industrial structure and the employment consequences of technical change. Oxf. Econ. Pap. 1987, 39, 552-567. [CrossRef]

36. Smolny, W. Innovations, prices and employment: A theoretical model and an empirical application for West German manufacturing firms. J. Ind. Econ. 1998, 46, 359-381. [CrossRef]

37. Malthus, T.R. Principles of Political Economy; First Edition 1836; M. Kelley: New York, NY, USA, 1964.

38. Sismondi, J.C.L. Nouveaux Principes d'Economie Politique ou de la Richesse dans ses Rapports avec la Population; First Edition 1819; Calmann-Levy: Paris, France, 1971.

39. Mill, J.S. Principles of Political Economy; First Edition 1848; M. Kelley: New York, NY, USA, 1976.

40. Sylos Labini, P. Oligopoly and Technical Progress; First Edition 1956; Harvard University Press: Cambridge, MA, USA, 1969.

41. Ricardo, D. Principles of Political Economy. In The Works and Correspondence of David Ricardo; Third Edtion 1821; Sraffa, P., Ed.; Cambridge University Press: Cambridge, UK, 1951; Volume 1.

42. Marshall, A. Principles of Economics; First Edition 1890; Macmillan: Basingstoke, UK, 1961.

43. Hicks, J.R. Capital and Time; Oxford University Press: Oxford, UK, 1973.

44. Crespi, F.; Ghisetti, C.; Quatraro, F. Environmental and innovation policies for the evolution of green technologies: A survey and a test. Eurasian Bus. Rev. 2015, 5, 343-370. [CrossRef]

45. Gagliardi, L.; Marin, G.; Miriello, C. The greener the better? Job creation effects of environmentally-friendly technological change. Ind. Corp. Chang. 2016, 25, 779-807. [CrossRef]

46. Meschi, E.; Taymaz, E.; Vivarelli, M. Trade, technology and skills: Evidence from Turkish microdata. Labour Econ. 2011, 18, S60-S70. [CrossRef]

47. Mitra, A.; Jha, A. Innovation and employment: A firm level study of Indian industries. Eurasian Bus. Rev. 2015, 5, 45-71. [CrossRef]

48. Haile, G.; Srour, I.; Vivarelli, M. Imported technology and manufacturing employment in Ethiopia. Eurasian Bus. Rev. 2017, 7. [CrossRef]

49. Sinclair, P.J.N. When will technical progress destroy jobs? Oxf. Econ. Pap. 1981, 31, 1-18. [CrossRef]

50. Layard, R.; Nickell, S. The causes of British unemployment. Natl Inst. Econ. Rev. 1985, 111, 62-85. [CrossRef]

51. Feldmann, H. Technological unemployment in industrial countries. J. Evol. Econ. 2013, 23, 1099-1126. [CrossRef]

52. Matuzeviciute, K.; Butkus, M.; Karaliute, A. Do technological innovations affect unemployment? Some empirical evidence from European countries. Economies 2017, 5, 48. [CrossRef]

53. Bogliacino, F.; Vivarelli, M. The job creation effect of R\&D expenditures. Aust. Econ. Pap. 2012, 51, 96-113. [CrossRef]

54. Piva, M.; Vivarelli, M. Technological change and employment: Is Europe ready for the challenge? Eurasian Bus. Rev. 2018, 8, 13-32. [CrossRef]

55. Cirillo, V.; Pianta, M.; Nascia, L. Technology and occupations in business cycles. Sustainability 2018, 10, 463. [CrossRef]

56. Van Reenen, J. Employment and technological innovation: Evidence from UK manufacturing firms. J. Labour Econ. 1997, 15, 255-284. [CrossRef]

57. Piva, M.; Vivarelli, M. Innovation and employment: Evidence from Italian microdata. J. Econ. 2005, 86, 65-83. [CrossRef] 
58. Barbieri, L.; Piva, M.; Vivarelli, M. R\&D, embodied technological change, and employment: Evidence from Italian microdata. Ind. Corp. Chang. 2018. [CrossRef]

59. Lachenmaier, S.; Rottmann, H. Effects of innovation on employment: A dynamic panel analysis. Int. J. Ind. Org. 2011, 29, 210-220. [CrossRef]

60. Ciriaci, D.; Moncada-Paternò-Castello, P.; Voigt, P. Innovation and job creation: A sustainable relation? Eurasian Bus. Rev. 2016, 6, 189-213. [CrossRef]

61. Van Roy, V.; Vertesy, D.; Vivarelli, M. Innovation and Employment in Patenting Firms: Empirical Evidence from Europe; IZA Discussion Papers 9147; Institute for the Study of Labor (IZA): Bonn, Germany, 2015.

62. Joint Research Centre-The Institute for Prospective Technological Studies. The EU RED Scoreboard; European Union: Brussels, Belgium, 2015.

63. Organisation for Economic Cooperation and Development. Frascati Manual_Proposed Standard Practice for Surveys on Research and Experimental Development; OECD: Paris, France, 2002.

64. Arellano, M.; Bond, S. Some tests of specification for panel data: Monte Carlo evidence and an application to employment equations. Rev. Econ. Stud. 1991, 58, 277-297. [CrossRef]

65. Blundell, R.; Bond, S. Initial conditions and moment restrictions in dynamic panel data models. J. Econ. 1998, 87, 115-143. [CrossRef]

66. Kiviet, J.F. On bias, inconsistency and efficiency of various estimators in dynamic panel data models. J. Econ. 1995, 68, 53-78. [CrossRef]

67. Judson, R.A.; Owen, A.L. Estimating dynamic panel data models: A guide for macroeconomists. Econ. Lett. 1999, 65, 9-15. [CrossRef]

68. Bun, M.J.G.; Kiviet, J.F. On the diminishing returns of higher order terms in asymptotic expansions of bias. Econ. Lett. 2003, 79, 145-152. [CrossRef]

69. Bruno, G.S.C. Estimation and inference in dynamic unbalanced panel data models with a small number of individuals. Stata J. 2005, 5, 473-500.

70. Bruno, G.S.C. Approximating the bias of the LSDVC estimator for dynamic unbalanced panel data models. Econ. Lett. 2005, 87, 361-366. [CrossRef]

71. Evangelista, R.; Savona, M. The impact of innovation on employment in services: Evidence from Italy. Int. Rev. Appl. Econ. 2002, 16, 309-318. [CrossRef]

(C) 2018 by the authors. Licensee MDPI, Basel, Switzerland. This article is an open access article distributed under the terms and conditions of the Creative Commons Attribution (CC BY) license (http:/ / creativecommons.org/licenses/by/4.0/). 